\section{Dina Kremsdorf \\ Valérie Thiers \\ Florianne Garreau \\ Albert Tran \\ Patrizia Paterlini \\ Guido Gerken \\ Bertrand Nalpas \\ Christian Bréchot}

\section{ADRESSES}

Dina Kremsdorf ${ }^{1}$ : chargée de recherche. Valérie Thiers $^{2}$ : technicien de recherche. Florianne Garreau ${ }^{1}$ : assistant ingénieur. Albert Tran 1,3 : docteur en médecine. Patrizia Paterlini $^{1}$ : docteur en médecine. Guido Gerken ${ }^{1}$ : docteur en médecine. Bertrand Nalpas ${ }^{3}$ : chargé de recherche. Christian Bréchot $1,2,3$, professeur, praticien hospitalier. 1 Inserm U. 75, CHU Necker, 156, rue de Vaugirard, 75015 Paris, France. 2 Inserm U. 163, laboratoire Hybridotest, Institut Pasteur, 25-28, rue du Docteur-Roux, 75015 Paris, France. 3 Inserm U.99, unité d'hépatologie, hôpital Laënnec, 42, rue de Sèvres, 75007 Paris,

\title{
Variabilité génétique du virus de l'hépatite $B$ et son expression sérologique
}

La réplication du virus de l'hépatite $B$ passe par une phase de transcription inverse d'un prégénome ARN. Cette implication de la transcriptase inverse pourrait expliquer la relative variabilité génétique du virus, dont il existe plusieurs sous-types entraînant des réactions sérologiques différentes, voire, dans un cas, une absence de synthèse de l'antigène e contrastant avec une multiplication virale active. Cette dernière anomalie est due à une mutation non-sens dans la région pré-C. Chez des malades avec hépatocarcinome ou hépatite chronique mais dépourvus de marqueurs sérologiques du virus $\mathrm{B}$, la polymerase chain reaction (PCR) a permis de détecter la présence d'ADN viral différent des virus B habituels par un petit nombre de mutations. La fréquence et le rôle de ces espèces moléculaires, isolées ou en association avec le virus de l'hépatite $C$, sont discutés.

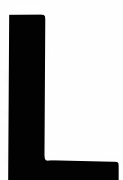

e sérum d'un sujet infecté par le virus de l'hépatite $B$ (VHB) peut contenir trois types de particules virales: les particules sphériques de $42 \mathrm{~nm}$ (particules de Dane), qui sont les particules virales infectieuses, ainsi que des particules sphériques $(22 \mathrm{~nm})$ ou en forme de filaments, qui sont uniquement constituées de l'enveloppe du virus* [1]. Les particules virales complètes comprennent une enveloppe externe et une capside interne, qui contient le génome viral et l'ADN polymérase. L'enveloppe du virus du VHB est formée de trois protéines associées à une bi-couche lipidique.

\footnotetext{
* Voir schémas, m/s no 4, vol.4, p.249 et $n^{\circ} 10$, vol. 4, p. 630 .
}

Chacune d'elles est codée à partir de régions bien définies du génome viral (figure 1). La protéine la plus représentée, dite «protéine majeure», est codée par le gène $S$. Les deux autres protéines, appelées «protéine moyenne» et «grande protéine », sont codées, respectivement, par les régions pré-S2/S et pré$\mathrm{Sl} / \mathrm{S} 2 / \mathrm{S}$. Ces trois protéines portent les déterminants de l'antigène de surface du virus (Ag HBs). Le diagnostic d'une infection par le VHB est fondé sur l'identification de l'Ag HBs par des techniques d'ELISA ou de RIA utilisant des anticorps polyclonaux ou actuellement essentiellement monoclonaux [2]. La région pré-S semble pouvoir se lier à un récepteur sur la membrane hépatocytaire. Elle interviendrait probablement dans la pénétration du virus dans les hépatocytes [3]. Deux antigènes, l'Ag $\mathrm{HBc}$ et l'Ag $\mathrm{HBe}$, sont 


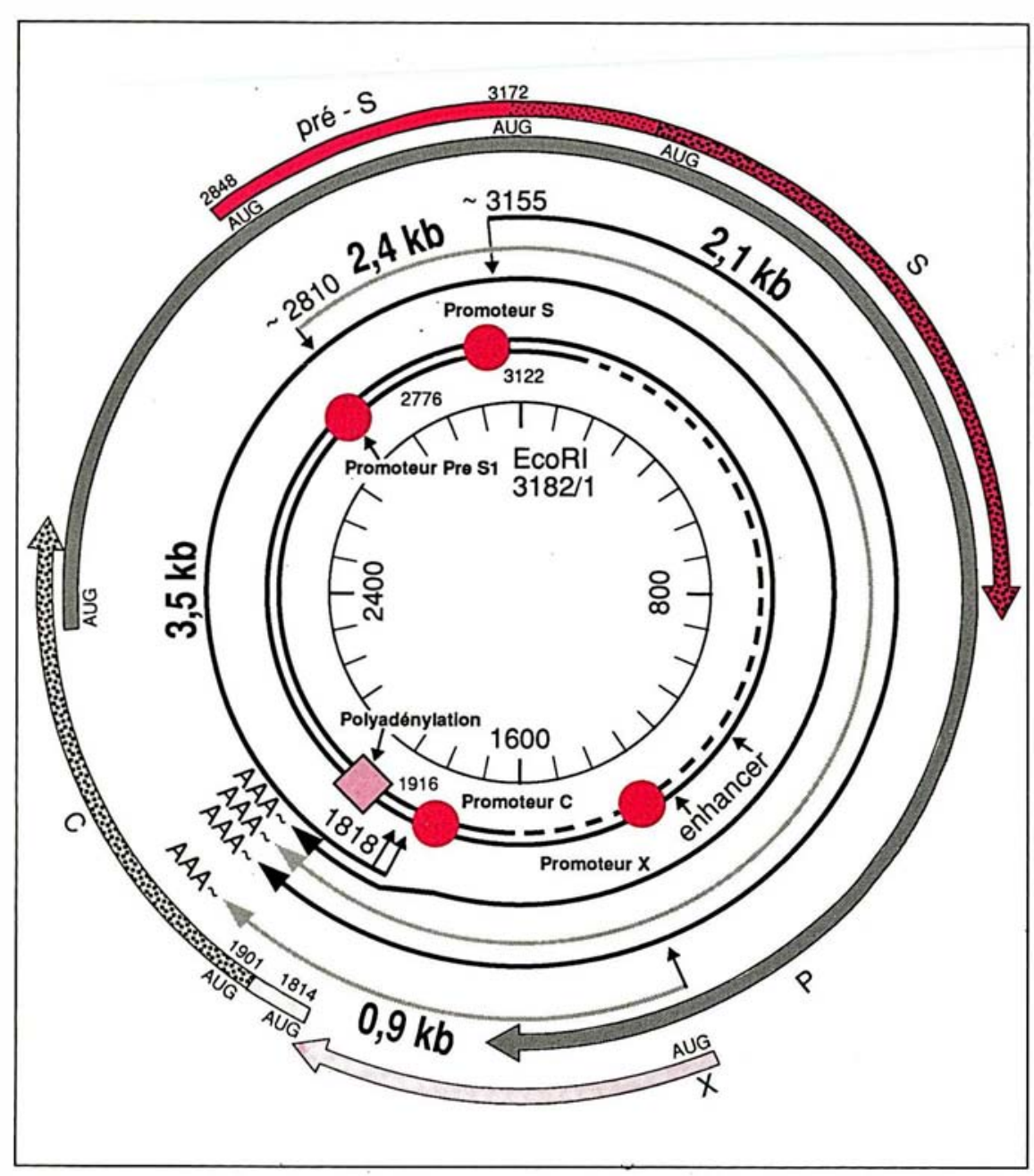

Figure 1. Structure et organisation génétique du génome de l'hépatite $B$. Le génome viral est composé de deux brins circulaires d'ADN; le plus court (brin t) est de longueur variable d'une particule virale à l'autre. Les flèches pleines correspondent aux quatre phases ouvertes de lecture codant pour les protéines de l'enveloppe (pré-S1 et S2,S) et de la capside (C), ainsi que pour une protéine transactivatrice $(X)$ et I'ADN polymérase (P). Ces protéines sont produites à partir de quatre types d'ARN. Les ARN de 2,1 et 2,4 kb codent pour les protéines d'enveloppe. Les ARN de 3,5 kb servent de prégénome et de messager pour la polymérase et les protéines de la capside. L'espèce de $0,9 \mathrm{~kb}$, enfin, code pour la protéine $X$. La graduation interne ainsi que la localisation des sites de restriction correspondent au génome de l'ayw3[1]. La région pré-C est représentée de manière agrandie avec $\left({ }^{*}\right)$ la localisation d'une mutation non-sens supprimant la synthèse d'Ag-e dans les cellules infectées par un variant du VHB.

identifiés sur la capside virale, seul l'Ag HBe étant sécrété dans le plasma. L'Ag $\mathrm{HBc}$ est codé par le gène $\mathrm{C}$ et l'Ag $\mathrm{HBe}$ par la région pré-C/C $[4,5]$. Les connaissances sur la structure des différents antigènes viraux ont évolué au cours des dernières années, en grande partie du fait de l'obtention d'anticorps monoclonaux. L'Ag HBs $\mathrm{m} / \mathrm{s} n^{\circ} 2$ vol. 6, féurier 90 protéine $\mathrm{S}$ dans des régions hydrophiles [7]. Deux paires de déterminants exclusifs (d ou y et $w$ ou $r$ ) sont associées au déterminant a [8]. Des sous-types «classiques » sont ainsi définis : adw, adr, ayw, ayr. En utilisant des anticorps monoclonaux et en se fondant sur leur affinité pour les particules virales, il a été possible d'établir une véritable «signature » de différents isolats [2]. De plus, très tôt au cours des études sur le VHB, des sérums ont été identifiés, qui donnent une réactivité «mixte», c'est-à-dire des tests positifs pour deux déterminants théoriquement exclusifs (par exemple adyw) [9]. La localisation des déterminants des régions pré-S1 et pré-S2 a été également précisée grâce à l'utilisation d'anticorps monoclonaux. Les protéines pré-S1 et pré-S2 semblent respectivement porter trois et deux épitopes majoritaires [10]. Enfin, pour les antigènes de la capside, l'Ag HBc a un épitope majoritaire, tandis que l'Ag $\mathrm{HBe}$ en a deux [11, 12].

L'évolution virologique d'une infection chronique par le virus B est marquée par la succession de deux phases: multiplication virale avec production de particules infectieuses de Dane, puis arrêt de la réplication avec persistance dans le foie de molécules d'ADN libres monomériques et, au moins dans certains cas, de séquences intégrées [1]. Dans notre expérience, l'intégration semble pouvoir être détectée dès le stade aigu de l'infection virale, mais ce point n'est pas définitivement établi. La durée et l'intensité de la multiplication virale varient d'un malade à l'autre. Le risque de développement d'une hépatite chronique puis d'une cirrhose est lié à la persistance de cette multiplication virale.

La réponse immunologique au VHB a longtemps été étudiée uniquement sur le plan humoral: les anticorps anti-HBs sont en effet les marqueurs de l'élimination du virus et de l'immunisation active ou passive. Une réponse de type cellulaire, dirigée contre les antigènes de surface (HBs et pré-S) et de la capside ( $\mathrm{HBc}$ ), est probablement également très importante. Des lymphocytes cytotoxiques $\mathrm{CD}^{+}{ }^{+}$et $\mathrm{CD} 4^{+}$interviendraient dans la clairance du virus en reconnaissant, sur la membrane des hépatocytes infectés, un antigène viral (pro- 


\section{RÉFÉRENCES}

1. Tiollais P, Pourcel C, Dejean A. The hepatitis B virus. Nature $1985 ; 317$ : 489-95.

2. Wands JR, Wong AM, Shorey J, Brown R, Marciniak RA, Isselbacher K J. Signature analysis of hepatitis B viral antigenic structure: analysis by monoclonal radio-immunoassay. Proc Natl Acad Sci USA 1984; 81 : 2237-41.

3. Neurath AR, Kent SBH, Strick N, Parker K. Identification and chemical synthesis of a host cell receptor binding site on hepatitis B virus. Cell $1986 ; 46: 429-36$.

4. Uy A, Bruss V, Gerlich WH, Kochel HC, Thomssen R. Precore sequence of hepatitis B virus inducing e antigen and membrane association of the viral core protein. Virology $1986 ; 155: 89-96$.

5. Weimer T, Salfeld J, Will H. Expression of hepatitis B virus core gene in vitro and in vivo. J Virol 1987 ; 61 : 5̊l09-13.

6. Courouce-Pauty AM, Plancon A, Soulier JP. Distribution of $\mathrm{HBs} \mathrm{Ag}$ subtypes in the world. Vox Sang 1983; $44: 197-211$.

7. Neurath AM, Kent SBH. Antigenic structure of hepatitis viruses. In: MHV Van Regenmortel, AR Neurath eds. Immunochemistry of viruses, the basis of serodiagnosis and vaccines. Amsterdam: Elsevier, 1985 ; 325-58.

8. Le Bouvier GL. The heterogeneity of Australia antigen. $J$ Infect Dis 1971 ; 123 : 671-5.

9. Okamoto H, Imai M, Tsuda F, Tanaka T, Miyakawa Y, Mayumi M. Point mutation in the $S$ gene of hepatitis $B$ virus for $a d / y$ or $\mathrm{w} / \mathrm{r}$ subtypic change in two blood donors carrying a surface antigen of compound subtype adyr or adwr. J Virol $1987 ; 61: 3030-4$.

10. Neurath AR, Kent SBH, Strick N, et al. Antibodies to synthetic peptides from the préS1 and preS2 regions of one subtype of the hepatitis B virus (HBV) envelope protein recognize all HBV subtypes. Molec Immun 1987 ; 24 : 975-80.

11. Ferns R, Tedder RS. Human and monoclonal antibodies to hepatitis $\mathrm{B}$ core antigen recognize a single immunodominant epitope. J Med Virol 1986 ; 19: 193-6.

12. Imai $\mathbf{M}$, Nomura $\mathbf{M}$, Gotanda $T$, et al. Demonstration of two distinct antigenic determinants on hepatitis $B$ e antigen by monoclonal antibodies. J Immunol 1982; bablement l'Ag $\mathrm{HBc}$ ) associé à des molécules HLA de classes I et II [13]. Les déterminants antigéniques des régions pré-S, $S$ et $C$, responsables des réponses cellulaires de type $B$ et $\mathrm{T}$, ont été localisés sur le génome viral (figure 2) [14].

Le génome du VHB est une petite molécule d'ADN de $3,2 \mathrm{~kb}$ qui présente une structure compacte (figure 1). Quatre phases ouvertes de lecture se chevauchant ont été décrites. Elles correspondent aux gènes codant pour l'enveloppe (régions pré-S1, S2 et gène $\mathrm{S}$ ), la capside (région pré-C et gène $C$ ), la polymérase (gène $\mathrm{P}$ ), et une protéine ayant une fonction de transactivation (gène $\mathrm{X}$ ) [1, 15]. La réplication du génome viral comprend une étape de transcription inverse permettant, à partir d'un ARN prégénome, la synthèse du brin (-) de l'ADN viral [15]. La structure du VHB et son mode de réplication l'ont fait comparer aux rétrovirus [16]. Cependant, contrairement aux rétrovirus, l'intégration de l'ADN du VHB n'est pas nécessaire à la réplication virale. L'existence dans le cycle de réplication du VHB d'une étape de transcription inverse suggère que l'ADN du VHB pourrait présenter un taux plus élevé de mutations que des virus à ADN «usuels» (comme les virus Herpes, par exemple); en effet les «erreurs » de la transcriptase inverse sont plus fréquentes que celles de l'ADN polymérase [16].

\section{Variabilité génétique du génome du VHB chez des sujets Ag HBs positifs}

A ce jour, la séquence nucléotidique de 18 VHB a été déterminée[17]. L'analyse des données de séquence montre une divergence de 0,2 à $11 \%$ entre les différentes séquences. En fonction de leur divergence, les isolats ont été répartis en quatre groupes, la variation génétique des isolats d'un même groupe étant inférieure à $6 \%$ [17]. Il est intéressant de noter qu'en utilisant cette classification, des sous-types distincts se retrouvent dans un même groupe. Cela semble suggérer que les différents sous-types dérivent d'un ancêtre commun. Bien que les bases moléculaires de la variation d'un sous-type à un autre restent imparfaitement connues, des études récentes ont montré que le changement d'un seul acide aminé dans la protéine $S$ était responsable soit du passage d'un déterminant antigénique à un autre (d/y ou $w / r$ ), soit de la perte de l'un des déterminants $[9,17,18]$. Ces substitutions ont été localisées dans la région carboxy-terminale de la protéine S (figure 2). Ce travail a donc indiqué pour la première fois qu'une variation très limitée de la séquence nucléotidique pouvait entraîner des modifications considérables de l'antigénicité des particules virales. De plus, ces études ont montré que les réactivités «mixtes » étaient dues à une hétérogénéité génétique reflétant la présence dans le sérum d'un mélange de particules portant différents déterminants antigéniques [9]. Parallèlement, le développement d'une nouvelle technique, dite polymerase chain reaction (PCR), permet l'amplification spécifique de séquences nucléotidiques et l'obtention rapide d'informations sur la séquence virale[19]. L'analyse de ces séquences nucléotidiques et l'utilisation des anticorps monoclonaux permettent de mieux préciser la notion de variabilité génétique de l'ADN du VHB et ses conséquences sur l'antigénicité des particules virales.

L'influence de faibles variations de la séquence protéique sur l'antigénicité est illustrée par l'analyse des séquences d'ADN du VHB trouvées dans le sérum d'un patient avant et après traitement par un anticorps monoclonal anti-HBs, après transplantation hépatique (G. Mahon, réunion " Hepatitis B viruses ", Cold Spring Harbor, 1989, p. 136 (abstr.)). En effet, dans le génome des particules virales qui persistent après traitement, on trouve des variations de la séquence nucléotidique qui entraînent des modifications d'acides aminés dans la région reconnue par l'anticorps anti-HBs. L'anticorps monoclonal semble donc agir comme un agent de sélection de particules mutantes.

Il est généralement admis que la détection de l'Ag $\mathrm{HBe}$ est un marqueur de l'infectiosité du sérum et que son absence est associée à l'arrêt de la réplication virale [1]. Cependant, la présence d'ADN viral dans le sérum de sujets sans $\mathrm{Ag} \mathrm{HBe}$ mais atteints d'hépatite chronique a été 


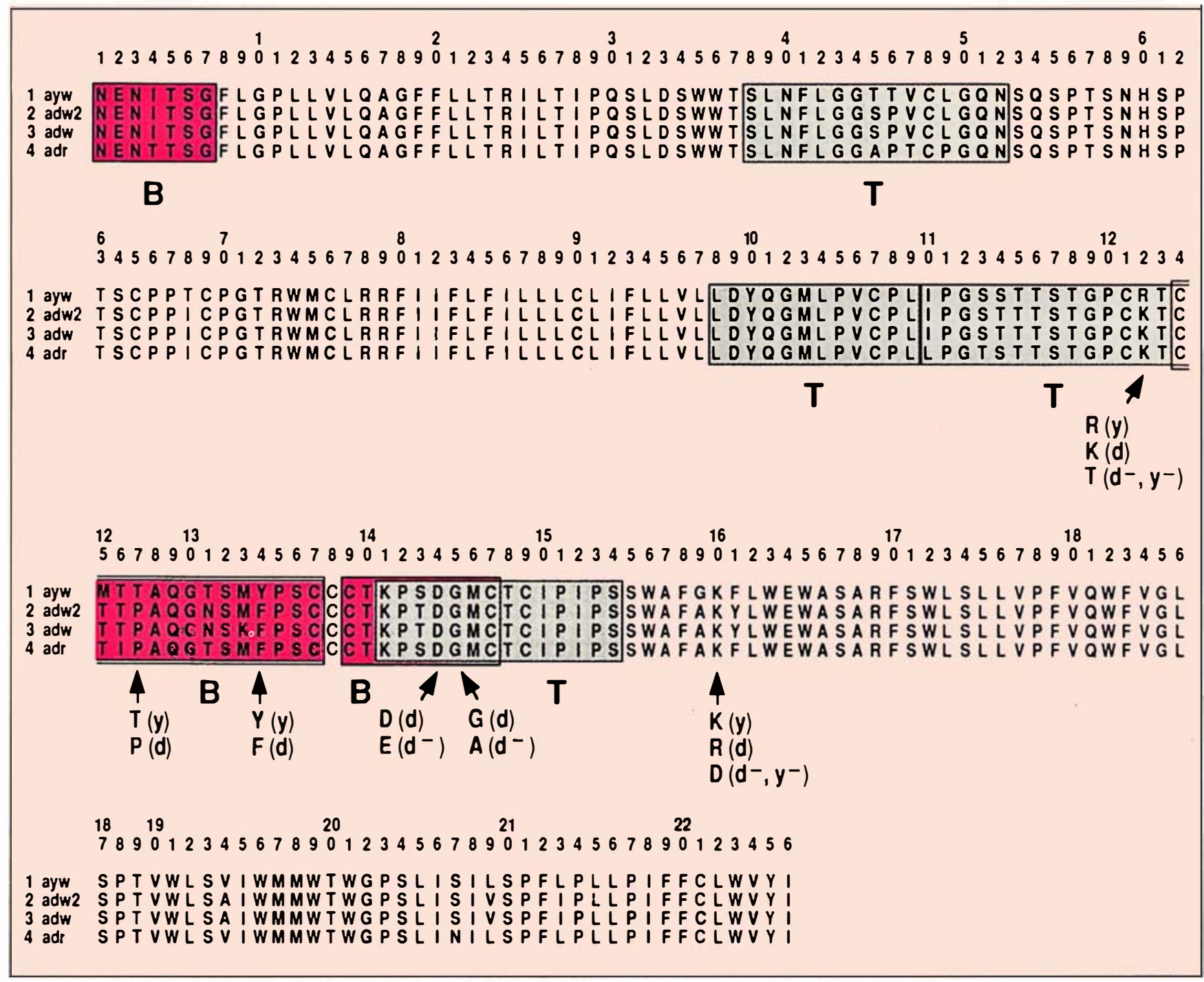

Figure 2. Représentation de la protéine codée par le gène S. Les lignes 1 à 4 représentent l'alignement des séquences en acides aminés de la protéine $S$ de quatre sous-types différents. Les blocs correspondent aux régions antigéniques responsables des réponses cellulaires de type $B(B)$ ou $T(T)$. Les acides aminés impliqués dans la modification de l'antigénicité sont indiqués par des têtes de flèche $[9,17,18]$. Entre parenthèses est noté le déterminant antigénique associé à chacun de ces acides aminés.

rapportée [20]. Ces patients sont le plus souvent originaires d'Europe du Sud ou d'Asie. Les bases moléculaires de l'existence d'une multiplication virale sans détection de l'Ag $\mathrm{HBe}$ ont été récemment élucidées [21, 22]. L'analyse, par PCR, de la région pré$C$ du génome viral de certains de ces isolats a en effet montré la présence dans la séquence virale d'un codon stop entraînant l'arrêt de la traduction de la protéine qui porte l'antigène $\mathrm{HBe}$.

L'une des questions posées par ces $\mathrm{m} / \mathrm{s} n^{\circ} 2$ vol. 6, féurier 90 travaux est de savoir si la variabilité génétique observée existe dès le début de l'infection, ou si elle apparaît au cours de l'évolution de la multiplication virale. Afin de répondre à cette question, nous avons entrepris l'analyse des séquences virales présentes, à cinq ans d'intervalle, chez un patient avec réplication virale et présentant les marqueurs sérologiques usuels d'une infection par le VHB. Trois régions du génome viral ont été étudiées : la région pré-S, le gène $S$ et le gène $C$. En début d'infection, seule une faible variabilité génétique a été observée par rapport à la séquence du sous-type adw2. En revanche, pour les prélèvements obtenus cinq ans après les premiers, une importante variabilité génétique (nombreuses mutations ponctuelles et remaniement du génome viral) a été observée. De plus, cette étude a mis en évidence l'existence d'une hétérogénéité moléculaire qui reflète la présence dans le sérum d'un mélange de particules virales. Ces résultats indiquent, au moins dans ce cas, une 


\section{RÉFÉRENCES}

13. Mondelli MU, Manns M, Ferrari C. Does the immune response play a role in the pathogenesis of chronic liver disease? Arch Pathol Lab Med 1988; 112 : 489-7.

14. Howard CR, Strick HJ, Brown SE, Steward MW. Towards the development of synthetic hepatitis B vaccines. In : Zuckerman ed. Viral hepatitis and liver disease. NY: Liss AR, Inc, 1987 ; 1094-101.

15. Ganem D, Varmus HE. The molecular biology of the hepatitis B viruses. Ann Rev Biochem 1987; 56 : 651-93.

16. Girones R, Miller RH. Mutation rate of the hepadnavirus genome. Virology 1989; 170 : 595-7.

17. Okamoto H, Tsuda F, Sakugawa $H$, et al. Typing hepatitis B virus by homology in nucleotide sequence: comparison of surface antigen subtypes. J Gen Virol 1988 ; 69 : 257583.

18. Okamoto H, Omi S, Wang Y, et al. The loss of subtype determinants in alleles, $d / y$ or $\mathrm{w} / \mathrm{r}$, on hepatitis B surface antigen. $\mathrm{J} \mathrm{Mol}$ Immunol $1989 ; 26$ : 197-205.

19. Thiers V, Nakajima E, Kremsdorf D, et al. Transmission of hepatitis B from hepatitis B seronegative subjects. Lancet 1988 ; ii : 1273-6.

20. Bonino F, Rosina F, Rozzetto M, et al. Chronic hepatitis in $\mathrm{HBs} \mathrm{Ag}$ carriers with serum HBV-DNA and anti-HBe. Gastroenterology $1986 ; 90: 1268-73$.

21. Carman WF, Jacyna MR, Hadzi-Yannis, et al. Mutation preventing formation of hepatitis $\mathrm{B}$ e antigen in patients with chronic hepatitis B infection. Lancet 1989 ; ii : 588-90.

22. Brunetto MR, Stemler M, Schödel F, et al. Identification of $\mathrm{HBV}$ variants which cannot produce precore derived $\mathrm{HBe} \mathrm{Ag}$ and may be responsible for severe hepatitis. Ita J Gastroenterol $1989 ; 21: 151-4$.

23. Bréchot C, Degos F, Lugassi C, et al. Hepatitis B virus DNA in patients with chronic liver disease and negative tests for hepatitis B surface antigen. $N$ engl J Med 1985 ; 312 : 270-6

24. Lai ME, Farci $P$, Figus $A$, Balestrieri $A$, Arnone M, Vyas GN. Hepatitis B virus DNA in the serum of sardinian blood donors negative for the hepatitis B surface antigen. Blood relation possible entre multiplication virale persistante et variabilité génétique (A. Tran, D. Kremsdorf $e t$ al., résultats non publiés).

L'ensemble de ces travaux montre donc l'existence d'une variabilité génétique du génome du VHB chez des sujets Ag HBs positifs. De plus, dans certains cas, la mutation à l'origine de la variation antigénique a pu être identifiée.

\section{Détection de séquences d'ADN du VHB chez des patients sans marqueur sérologique d'une infection par le VHB}

Des études antérieures ont montré que des séquences d'ADN viral pouvaient être détectées dans le foie et le sérum de malades atteints d'hépatite chronique ou aiguë, tandis que l'Ag HBs n'était pas détecté par des anticorps polyclonaux [19, 23-25]. L'ADN du VHB est ainsi détecté dans le sérum et dans le foie d'environ 10 et $40 \%$, respectivement, des malades atteints d'hépatite chronique et négatifs pour l'Ag HBs et chez environ $11 \%$ d'alcooliques chroniques sans carcinome hépatocellulaire. Ces chiffres incluent des sujets ayant des anticorps anti-HBs et anti-HBc et des patients n'ayant aucun marqueur sérologique d'un contact avec le VHB. L'ADN du VHB a également été détecté dans $80 \%$ des cancers primitifs du foie $\mathrm{Ag}$ HBs négatifs associés à une cirrhose.

Les sérums de trois patients négatifs pour l'Ag HBs par des tests immunologiques standard, mais $\mathrm{Ag} \mathrm{HBs}$ positifs en utilisant des anticorps monoclonaux, ont été plus particulièrement étudiés (D. Kremsdorf et al., réunion "Hepatitis $B$ viruses», Cold Spring Harbor, 1989, p. 127 (abstr.) soumis pour publication) (Tableau I). Les tests sérologiques ont montré que seul l'un de ces sérums était positif pour la présence d'anticorps anti-HBs et anti-HBc. Des séquences d'ADN du VHB ont été détectées dans le sérum des trois patients en utilisant des techniques classiques de détection (spot test ou hybridation sur réplique) ainsi qu'en utilisant la PCR. Afin de démontrer la présence de particules infectieuses, les sérums ont été injectés à des chimpanzés immunisés ou non contre le
VHB [19, 25]. L'injection des sérums a induit une élévation des transaminases et l'apparition de lésions hépatiques compatibles avec une hépatite aiguë (figure 3). Ces expériences ont confirmé la présence de particules virales transmissibles dans les sérums. Il est à noter que cette transmission a également été observée chez des chimpanzés positifs par l'anti-HBs, qui sont théoriquement protégés contre une infection par le virus $B$ (des résultats semblables ont été obtenus par le groupe de C. Trépo) [26]. La détermination des marqueurs sérologiques présents chez ces chimpanzés a montré deux types de profil. Pour deux des chimpanzés, aucun marqueur n'a été détecté en utilisant des anticorps polyclonaux. Seule l'apparition tardive de l'Ag HBs, détectée par des anticorps monoclonaux, a été observée. En revanche, pour le dernier chimpanzé, les marqueurs sérologiques usuels d'une infection par le VHB ont été identifiés. Ceci montre la présence de particules du VHB « normales », en quantité faible chez le malade.

Ces résultats mettent donc en évidence la possibilité d'une multiplication virale sans détection des marqueurs sérologiques usuels. Une telle variation d'expression peut être due à une faible réplication virale ou à une modification de l'exportation des protéines virales. Des anomalies de la réponse immunitaire de l'hôte, incluant des complexes immuns circulants, peuvent également intervenir. Enfin, des modifications génétiques peuvent être à la base de la variation de l'expression antigénique. Afin de tester cette dernière hypothèse, la séquence nucléotidique complète des trois isolats a été déterminée. Dans ce but, la totalité des génomes viraux a été amplifiée par PCR et les produits d'amplification ont été clonés et séquencés. L'analyse des données de séquence a montré que les trois isolats ne divergeaient du prototype du sous-type ayw que par quelques mutations ponctuelles (moins de $1 \%$ ). La plupart de ces mutations sont situées sur la troisième base du codon et, donc, ne provoquent pas de changement d'acide aminé. De plus, aucune de ces mutations n'a été localisée dans des régions de régulation du virus et 


\begin{tabular}{|c|c|c|c|c|c|c|c|}
\hline \multicolumn{8}{|c|}{$\begin{array}{c}\text { DÉTECTION DES MARQUEURS SÉROLOGIQUES DU VHB ET DES SÉQUENCES D'ADN DU VHB } \\
\text { DANS LE SÉRUM ET LE FOIE DE TROIS PATIENTS SÉRONÉGATIFS }\end{array}$} \\
\hline \multirow[t]{2}{*}{ Patients } & \multirow[t]{2}{*}{$\begin{array}{l}\text { Histologie } \\
\text { du foie }\end{array}$} & \multicolumn{4}{|c|}{ Marqueurs sérologiques du VHB(1) } & \multicolumn{2}{|c|}{$\begin{array}{l}\text { Séquence d’ADN } \\
\text { du VHB(2) }\end{array}$} \\
\hline & & AgHs & M. AgHBs & Anti-HBs & Anti-HBc & St & PCR \\
\hline No 1 & Normale & - & + & - & - & + & + \\
\hline № 2 & HA & - & + & - & - & + & NT \\
\hline № 3 & Normale & - & + & + & + & + & + \\
\hline
\end{tabular}

11). La présence dans les sérums de l'AgHBs et des anticorps anti-HBs et anti-HBc a été déterminée par dosage radio-immunologique (RIA). L'AgHBs a été également mesuré en utilisant des anticorps monoclonaux (M. AgHBs).

(2). Des séquences d'ADN du VHB ont été recherchées, soit par des techniques standard (St) (hybridation sur réplique ou spot test), soit par amplification génique (PCR) de la région $3^{\prime}$ terminale du gène $S$.

HA: hépatite aiguë; NT: non testé.

elles n'introduisent pas de codons de fin de traduction. Cependant, pour les régions pré-S, $\mathrm{S}$ et $\mathrm{C}$, la plupart des substitutions ont été localisées dans des régions connues comme correspondant à des domaines antigéniques (Tableau II). Ces mutations pourraient être impliquées dans les variations sérologiques observées chez ces patients. Un argument définitif en faveur de cette hypothèse ne pourra être apporté que par l'expression des gènes mutés et l'analyse des protéines virales. La faible variabilité génétique des isolats étudiés est probablement liée à la faible réplication virale observée chez les patients et les chimpanzés à partir desquels ils ont été isolés. En effet, des études ont montré la présence d'une faible quantité de particules virales dans le sérum et d'ADN du VHB dans le foie de la plupart d'entre eux. De plus, les expériences de transmission aux chimpanzés ont révélé l'existence d'une longue période d'incubation (trois à quatre mois) (interaction VHB/VHC, voir plus loin).

\section{Les implications cliniques de la détection du VHB dans le sérum de sujets séronégatifs}

Les travaux antérieurs, rapportant la présence de l'ADN du VHB dans des particules infectieuses, suggéraient que certaines hépatites définies, par exclusion, comme non- $A$, non- $B$ pouvaient être liées au virus de l'hé$\mathrm{m} / \mathrm{s} n^{\circ} 2$ vol. 6, février 90 patite $B$ [19, 23-25]. Ces résultats concordent avec des observations cliniques montrant la possibilité rare de transmission de l'hépatite $B$ après transfusion sanguine, cela malgré le dépistage systématique de l'Ag HBs dans le sang des donneurs.

Ces observations restent cependant un sujet de controverse, car plusieurs groupes n'ont pas détecté de séquences virales dans le sérum de sujets séronégatifs. Cela pourrait être expliqué par un niveau insuffisant de spécificité et de sensibilité des tests utilisés pour la détection des séquences virales [27, 28]. Le type de virus en cause a également été discuté : s'agissait-il d'un nouveau virus «relié » au VHB [28] ou du virus B porteur ou non de modifications génétiques [19] ? Comme le montrent les résultats rapportés dans le chapitre précédent, la PCR a permis de démontrer de façon définitive la présence de l'ADN du VHB dans le sérum de patients séronégatifs. L'analyse des séquences virales a montré que les génomes de VHB ne différaient des sous-types précédemment décrits que par un nombre limité de mutations ponctuelles. Déterminer si les génomes viraux mutés s'expriment serait bien sûr

\begin{tabular}{|c|c|c|c|c|c|}
\hline \multicolumn{6}{|c|}{ Tableau II } \\
\hline & $\begin{array}{l}\text { Position } \\
\text { des acides } \\
\text { aminés }\end{array}$ & 1 & 2 & 3 & $\begin{array}{l}\text { Localisation } \\
\text { d'épitopes } \\
\text { immunodominants }\end{array}$ \\
\hline Pré-S & $\begin{array}{r}90 \\
144 \\
149 \\
150\end{array}$ & $\begin{array}{l}\text { Leu } \rightarrow \text { Pro } \\
\text { Pro } \rightarrow \text { His } \\
\text { Leu } \rightarrow \mathrm{lle}\end{array}$ & $\begin{array}{l}\text { Ser } \rightarrow \text { Thr } \\
\text { Leu } \rightarrow \text { Pro }\end{array}$ & $\begin{array}{l}\text { Ser } \rightarrow \text { Thr } \\
\text { Leu } \rightarrow \text { Pro }\end{array}$ & $\begin{array}{c}\text { aa } 81 \text { à } 96 \\
\text { aa } 114 \text { à } 154\end{array}$ \\
\hline$S$ & $\begin{array}{r}20 \\
129\end{array}$ & Phe $\rightarrow$ Ser & & $\mathrm{Gln} \rightarrow \mathrm{His}$ & aa 124 à 147 \\
\hline Pré-C/C & $\begin{array}{r}58 \\
69 \\
159\end{array}$ & Glu $\rightarrow$ Asp & Asp $\rightarrow$ His & Pro $\rightarrow$ Ala & $\begin{array}{c}\text { aа } 56 \text { à } 64 \\
\text { aа } 159 \text { à } 169\end{array}$ \\
\hline
\end{tabular}

aa : acides aminés. 


\section{RÉFÉRENCES}

25. Wands JR, Fujita YK, Isselbacher $\mathrm{KJ}$, et al. Detection and transmission of hepatitis $B$ virus variant. Proc Natl Acad Sci USA 1986 ; 83 : 6608-12.

26. Trepo C, Degos F, Vitvitski L, et al. Evidence for a transmissible non-A non-B agent inextricably linked with hepatitis B virus in: G. Vyas, J. Dienstag, J. Hoofnagle ed. Viral he patitis and liver disease. Grune and Stratton, Inc, $1984 ; 355-65$

27. Yokusuda O, Omata M, Imazeki F, et al. Hepatitis B virus RNA transcripts and DNA in chronic liver disease. $N$ Engl J Med 1986 ; $315: 1187-92$

28. Fong TL, Govindarajan S, Valinluck B, Redeker AG. Status of hepatitis B virus DNA in alcoholic liver disease : a study of a large urban population in the united states. Hepatology $1988 ; 8: 1602-4$.

29. Choo QL, Kuo G, Weiner AJ, Overby LR, Bradley DW, Houghton M. Isolation of a cDNA clone derived from a blood borne non-A, non-B viral hepatitis genome. Science $1989 ; 244: 359-62$

30. Kuo G, Choo $\mathrm{OL}$, Alter $\mathrm{HJ}$, et al. An assay for circulating antibodies to a major etiologic virus of human non-A, non-B hepatitis. Science $1989 ; 244: 362-4$.

31. Nalpas B, Berthelot P, Thiers V, et al. Hepatitis $B$ virus multiplication in the absence of usual serological markers ; a study of 146 chronic alcoholics. J Hepatol $1985 ; 1$ : 89-97.

32. Sakamoto S, Hirohashi S, Tsuda T, et al. Increasing incidence of hepatocellular carcinoma possibly associated with non-A, non-B hepatitis in Japan, disclosed by hepatitis B virus DNA analysis of surgically resected cases. Cancer Res 1988; 48: 7294-7.

33. Walter E, Blum HE, Meir P, et al. Hepatocellular carcinoma in alcoholic liver disease : no evidence for a pathogenic role of hepatitis B virus infection. Hepatology 1988 $8: 754-8$.

34. Korba B, Wells F, Baldwin B, et al. Hepatocellular carcinoma in woodchuck hepatitis virus infected woodchucks: presence of viral DNA in tumor tissue from chronic carriers and serologically recovered from acute infections. Hepatology $1989 ; 9: 461-70$.

35. Giacchino R, Pontisso P, Navone C, et al. Hepatitis B virus (HBV)-DNA-positive hepatocellular carcinoma following hepatitis B virus infection in a child. $J$ Med Virol 1987 ;
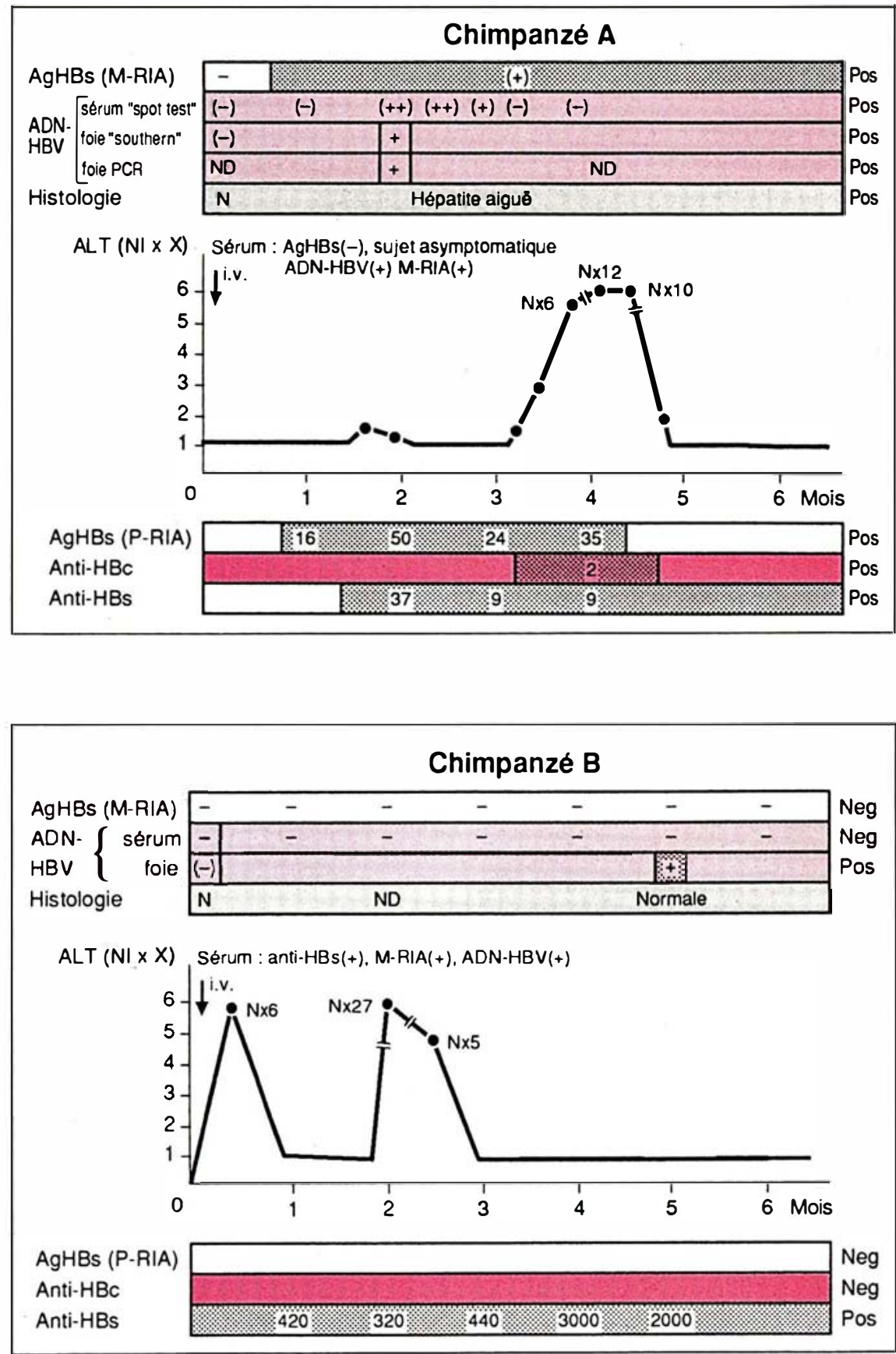

Figure 3. Résultats des tests sérologiques, histologiques et virologiques après inoculation de sérums séronégatifs à deux chimpanzés. Chimpanzé $A$ : après injection, une élévation des transaminases (ALT, alanine aminotransférase) et l'apparition des marqueu, s sérologiques usuels d'une infection par le VHB (Ag HBs, anti-HBc et anti-HBs) ont été observées. Chimpanzé B: I'injection du sérum a induit deux pics d'élévation des transaminases. Ce chimpanzé avait été auparavant infecté par un virus $B$ *classique * les taux d'anticorps anti-HBs se sont considérablement élevés de façon retardée (4 mois). L'Ag HBs et l'anti-HBc n'ont pas été identifiés (pour d'autres chimpanzés, l'Ag HBs a été identifié uniquement avec des anticorps monoclonaux et de façon retardée). Pour ce chimpanzé, une séroconversion anti-VHC a été détectée.

Blocs inférieurs : marqueurs sérologiques du VHB. P-RIA : anticorps polyclonaux; Blocs supérieurs : anticorps monoclonaux (M-RIA), ADN du VHB et histologie. $N$ normale; ND : non déterminé. 
essentiel pour savoir si de nouveaux épitopes viraux doivent être testés dans une optique à la fois de diagnostic et de vaccination.

Les questions qui restent posées concernent la fréquence du phénomène et la place des infections par le VHB par rapport à celles liées au virus de l'hépatite $C$. En effet, un nouveau virus, le virus de l'hépatite $\mathrm{C}$ (VHC), a récemment été identifié [29]. Il est clairement impliqué dans la majorité des hépatites nonA, non-B post-transfusionnelles et sporadiques [30]. Dans notre expérience, nous avons fréquemment détecté les deux virus dans le sérum des malades. De plus, certaines des hépatites non- $A$, non- $B$ sont négatives pour les anticorps anti-VHC et positives pour l'ADN-VHB.

L'hypothèse importante à tester sera donc celle des interactions potentielles entre VHC et VHB. On ne possède pas actuellement de données définitives sur ce point. Cependant, il a été suggéré que le VHC pourrait diminuer la réplication virale. Il est donc possible que lors d'une coinfection VHC-VHB l'expression du virus B soit diminuée. Des expériences de transmission au chimpanzé pourraient confirmer une telle hypothèse. En effet, nous avons pu observer, chez un animal infecté par l'injection d'un sérum négatif pour l'Ag HBs mais positif pour l'ADNVHB, deux épisodes successifs d'hépatite aiguë. Parallèlement, la transmission de particules virales B et une séroconversion avec détection retardée d'anticorps anti-VHC ont été observées; ce résultat indique donc clairement l'association des deux infections virales.

\section{Cancer primitif du foie chez des sujets Ag HBs négatif: rôle potentiel du VHB}

La prévalence d'un test positif pour l'Ag HBs, chez des malades avec cancer primitif du foie, varie considérablement dans le monde [1]. En Asie et en Afrique noire, 60 à $80 \%$ des sujets sont positifs pour l'Ag HBs. En revanche, en Europe et aux USA, la prévalence est beaucoup plus faible. En France, par exemple, seulement 20 à $30 \%$ des malades sont positifs pour l'Ag HBs. Les facteurs étiologiques impliqués dans le déve$\mathrm{m} / \mathrm{s} n^{\circ} 2$ vol. 6, février 90 loppement des cancers primitifs du foie chez des malades négatifs pour l'Ag HBs (70 à $80 \%$ des cas) restent mal connus. Des études, utilisant la technique d'hybridation sur réplique, ont montré, dans environ $80 \%$ des tumeurs associées à une cirrhose, la présence de séquences d'ADN de VHB [23, 31]. Des séquences virales ont en revanche été plus rarement détectées dans des tumeurs se développant sur un foie non cirrhotique [23]. Les profils de restriction observés sont compatibles avec la présence, soit de séquences virales intégrées dans le génome cellulaire, soit de formes libres, mais le plus souvent sans intermédiaire de réplication [23, 31]. Contrairement aux tumeurs positives pour l'Ag $\mathrm{HBs}$, le nombre de copies d'ADN viral par cellule est faible (environ 0,01 à 0,1 copie par cellule). Des résultats contradictoires ont cependant été rapportés: des études réalisées au Japon, aux USA et en Allemagne n'ont pas montré de détection d'ADN viral dans des tumeurs négatives pour l'Ag HBs [28, 32, 33]. Ces résultats divergents peuvent être liés au faible nombre de génomes viraux par cellule (et, donc, à des différences de sensibilité et de spécificité). Des variations épidémiologiques dans la fréquence d'exposition au virus doivent également être considérées.

La PCR nous a récemment permis de confirmer la présence de séquences d'ADN de VHB dans 17 sur 28 tumeurs (P. Paterlini et al., soumis pour publication). Ces tumeurs proviennent de régions où la prévalence de l'infection par le VHB est variable (Afrique, Italie, Japon et France). La PCR a également permis de mettre en évidence l'existence de transcrits viraux dans ces tumeurs. Ces résultats indiquent que la persistance de l'ADN et de l'ARN viraux pourrait représenter un facteur de risque pour le développement des cancers primitifs du foie. L'infection virale doit donc être prise en compte dans la discussion des facteurs pathogéniques d'apparition de ces tumeurs. Il est intéressant de noter que ces observations sont en accord avec celles décrites chez la marmotte après infection par le virus de l'hépatite de la marmotte (WHV) [34]. Certains animaux développent en effet une tumeur après inoculation du virus malgré la négativation du sérum pour l'antigène de surface (WHV $\mathrm{AgS})$. Alors que les tumeurs provenant d'animaux positifs pour le WHV AgS contiennent environ 100 à 1000 copies d'ADN viral par cellule, un faible nombre de copies d'ADN viral intégré $(0,1$ à 0,01 copie par cellule) a été détecté dans des tumeurs se développant chez des animaux après séronégativation. Chez l'homme, l'hypothèse selon laquelle la persistance de séquences d'ADN viral après la disparition de l'Ag HBs dans le sérum constitue un facteur de risque pour le développement de cancers primitifs du foie peut rendre compte des données épidémiologiques actuellement disponibles. En effet, alors que dans les premières études prospectives le développement de cancers du foie n'avait été observé que chez des sujets Ag HBs positif, des données récentes ont montré l'apparition de tumeurs chez certains sujets $\mathrm{Ag} \mathrm{HBs}$ négatif, mais avec des signes d'une exposition antérieure au virus (anti-HBc et anti-HBs positifs) $[23,35]$.

En France, la forte prévalence de maladies chroniques du foie liées à l'alcoolisme chronique a permis d'analyser, dans ce groupe, les conséquences d'une infection par le VHB [31]. Les alcooliques chroniques sont fréquemment exposés à la fois au virus B et au virus C. Environ $30 \%$ des alcooliques chroniques sont positifs à la fois pour l'anti-HBc et l'anti-HBs. Des résultats encore préliminaires ont montré une forte prévalence de tests anti-VHC positifs (B. Nalpas et al., résultats non publiés). La forte prévalence de séquences d'ADN de VHB $(80 \%)$ détectées chez des sujets avec cirrhose alcoolique et cancer primitif du foie contraste avec le faible taux $(10 \%)$ de résultats positifs chez des alcooliques chroniques ayant des hépatopathies non cancéreuses.

Le rôle précis du VHB dans la genèse des tumeurs reste cependant inconnu. Le virus pourrait essentiellement intervenir en induisant une cirrhose qui représente un état prétumoral; cependant, l'ADN du VHB peut aussi être détecté dans des tumeurs se développant sur un foie non cirrhotique. L'infection virale pour- 
rait intervenir dans l'initiation de la transformation cellulaire, le VHB n'étant plus nécessaire pour les étapes suivantes de la carcinogenèse. Des interactions entre VHB et VHC doivent également être considérées. Le génome du VHC ne s'intègre pas dans l'ADN cellulaire. Il pourrait jouer un rôle important par le biais de la nécrose hépatocytaire et de la régénération cellulaire secondaire à cette nécrose. Dans cette hypothèse, le virus $\mathrm{C}$ interviendrait comme un facteur de promotion dans la cancérogenèse. Il faut souligner qu'aucune donnée expérimentale ne permet actuellement de valider ces différentes hypothèses

\section{TIRÉS A PART}

C. Bréchot.

\section{Summary}

Genetic variability of hepatitis B virus and the serological expression of the viral infection

The importance of the genetic variability of the hepatitis $B$ virus (HBV) in the clinical and serological expression of the viral infection has been underestimated. It has been recently shown that a single aminoacid substitution in the viral surface gene can lead to the change from one subtype to another. Polymerase chain reaction (PCR) has allowed to increase the sensitivity of detection and to analyze a larger number of viral nucleotide sequences. In some $\mathrm{HBV}$ chronic carners, mutations in the pre-C region have been identified which account for a viral multiplication despite absence of $\mathrm{HBe} \mathrm{Ag}$ secretion. In seronegative patients with chronic hepatitis and/or primary liver cancer, HBV DNA sequences were detected. By using PCR, we were able to characterize some of these $\mathrm{HBV}$ isolates. Their nucleotide sequences differ from regular $\mathrm{HBV}$ subtype by only few point mutations. The genetic variability, observed both in $\mathrm{HBs} \mathrm{Ag}$ positive and negative subjects, might be related to the reverse transcriptase step used in HBV DNA replication and therefore be linked to the extent and duration of viral multiplication. 